\title{
Repurposing scientific writing in conservation biology
}

\author{
Robert Boyd, Christopher Basgier, Claire Wilson*
}

$2 / 3 / 2020^{\dagger}$

\begin{abstract}
Scientists and writing studies scholars agree that students need to be able to repurpose scientific knowledge across audiences, goals, and genres. This article offers a much-needed, practical example of an assignment that allows students to work towards these goals. Working collaboratively, a faculty member from biology, a Writing Across the Curriculum (WAC) administrator, and an Encyclopedia of Alabama (EOA) editor redesigned a conservation biology course assignment around communication with multiple audiences. The assignment required students to produce a webpage about a rare species in Alabama that fulfills the technical, scientific writing component of the course and then repurpose that webpage into an entry for EOA aimed at a non-expert audience. We elaborate on the context in which the repackaging assignment developed, explain how it fits with student learning outcomes in biology, and share themes we noticed in students' reflections on the practice of repurposing their writing.
\end{abstract}

Over the last decade, national conversations about science education have included discussions about the place of writing in the intellectual and professional work of science. In the context of the biological sciences, for example, Vision and Change (Brewer \& Smith, 2009) - a collaboration among the National Science Foundation, the Howard Hughes Medical Institute, and the American Association for the Advancement of Sciencedescribed effective written communication as "a basic skill for participating in inclusive and diverse scientific communities" (p. 15). Writing is fundamental to the production of scientific knowledge (Bazerman, 1988), the development of scientific identities (Moon, Gere, \& Shultz, 2018; Tardy, 2005), and the learning of science (Gere, Limlamai, Wilson, Saylor, \& Pugh, 2019). Increasingly, students must be able to write for diverse, nonscientific audiences. In conservation biology - the focus of this article - the developing global conservation crisis, sometimes referred to as the sixth mass extinction (Ceballos

\footnotetext{
*Auburn University, boydrob@auburn.edu. Copyright 2020 Robert Boyd, Christopher Basgier, and Claire Wilson. This work is licensed under a Creative Commons Attribution-NonCommercial 4.0 International License (http://creativecommons.org/licenses/by-nc/4.0/).

${ }^{\dagger}$ Submitted, 4/23/2019; Accepted, 10/3/2019.
} 
et al., 2015), demands that scientists increase efforts to communicate with a broader audience, including policy makers (Cook, Mascia, Schwartz, Possingham, \& Fuller, 2013). In the United States, the recent political environment has resulted in increased attention on the need for scientists to communicate effectively with politicians to ensure that public policy is informed by scientific information (Schaal, 2017).

Writing studies scholars often call the ability to communicate knowledge across rhetorical situations repurposing. Prior and Shipka (2003) define repurposing as "the re-use and transformation of some text/semiotic object" (p. 17), such as popularizing a scientific article or reworking language from a grant proposal into a research article. This latter example supports Kevin Roozen's (2010) claim that repurposing is "a key strategy for participating in advanced disciplinary activities" that occurs in the normal course of teaching and scholarship (p. 321). Furthermore, the ability to repurpose writing knowledge across contexts is a key marker of communicative success for scientists, engineers, and other STEM professionals who work in industry (Artemeva, 2005). As science students advance in their education and their careers, they will need to have greater facility with repurposing in order to communicate effectively and address current and future scientific and technical challenges.

The Department of Biological Sciences (DBS) at Auburn University agrees. In 2017, DBS undertook a major overhaul of its departmental Student Learning Outcomes (SLOs). Boyd was a key leader in these changes, having brought knowledge from recent participation in an NSF-funded Partnership for Undergraduate Life Science Education (PULSE) workshop and an NSF-funded Symposium on Course-Embedded Undergraduate Research Experiences (CUREs). He worked with his colleagues to revamp a set of seven departmentwide SLOs. Since then, DBS faculty members have been engaged in efforts to define, assign, and assess a written communication outcome that includes the ability to communicate to varied scientific and public audiences.

In short, scientists and writing studies scholars agree that students need to be able to repurpose scientific knowledge across audiences, goals, and genres. This article offers a much-needed, practical example of an assignment designed with this goal in mind. Specifically, we discuss a collaboration among a faculty member in DBS (Boyd), an administrator in the Office of University Writing (OUW; Basgier), and an editor for the Encyclopedia of Alabama (EOA; Wilson). Working together, we redesigned an assignment in Conservation Biology around communication with multiple audiences. The assignment required students to produce a webpage about a rare species in Alabama that fulfills the technical, scientific writing component of the course and then repurpose it as an EOA entry aimed at a non-expert audience. In what follows, we will elaborate on the context in which the repurposing assignment emerged, explain how it fits with SLOs in DBS, and share themes we noticed in students' reflections on the assignment. 


\section{Course Context}

Conservation Biology (BIOL 5090/6090) is a mixed advanced undergraduate/graduate course required of undergraduates focusing on conservation and biodiversity as part of the Organismal Biology major offered by DBS. Boyd has taught it for eleven years. Historically, the course has included in-class exams, summaries of conservation-oriented news articles, and Rare Species Webpages. Originally, Boyd required each student to produce two webpages, consisting of information that conservation professionals include in Species Recovery Plans for species listed as "endangered" or "threatened" under the U.S. Endangered Species Act. One webpage could be about a rare Alabama organism of the students' choosing. The other had to be about a non-vertebrate (plant or invertebrate animal) to steer students away from writing solely about mammals because Boyd wanted students to understand that many other species play important roles in Alabama's natural communities and thus deserve conservation attention. Webpages used a format and style typical of technical scientific papers, often drawing on Species Recovery Plans and scientific literature. Students had to search the scientific literature effectively for relevant information and most had been exposed to this type of task at prior points in their education. To assist students in their literature search, the subject-area librarian for DBS (Patricia Hartman) constructed a "Subject Guide" that provided search tips and information on useful databases and web resources to aid students in finding credible information. Broadly, this original assignment aimed to support students' higher-order thinking, such as synthesis of information. It also helped students acquire content knowledge, develop information literacy skills, and practice scientific writing, all of which were among the newly established SLOs for DBS.

As a leader of curricular reform, Boyd wanted to rework his course in keeping with the new SLOs as a model for his colleagues. Basgier had already begun consulting with the department on some of these curricular changes, so Boyd asked him to help develop the new course assignments. Simultaneously, Wilson had been involved for several years in selecting some of the better webpages for development into EOA articles, which offered those students the chance to communicate with both scientific and non-scientific audiences. The online EOA, free to anyone with Internet access, was launched in 2008 with the goal of providing information on all aspects of the state, including history, geography, arts and literature, and the environment. Its content is produced by scholars and professional writers and structured to be accessible to non-experts, making it an ideal venue for communicating scientific knowledge broadly.

Working together, the three authors redesigned the assignment to support the new, expanded DBS written communication SLO. The aim in redesigning the assignments was not to assess DBS SLOs directly in the course, but rather to give students opportunities to develop the knowledge, skills, and abilities that support the outcomes. The revised assignment required students to compose just one approximately 5,000-word Rare Species Webpage and then repurpose that webpage into a 1,000-word EOA article. EOA articles were required to be accessible to non-experts and aimed at a $9^{\text {th }}$-grade reading level (according to Microsoft Word's built-in Flesch-Kincaid readability score). Thus, students 
had to condense and revise the technical content of the webpage into a form that non-experts could read and understand.

\section{Assignment Overview}

Student selection of rare species began the first day of class. Students chose a species from a publication by the Alabama Natural Heritage Program (Alabama Natural Heritage Program, 2017), which ranks each species' rarity on state and global levels. Students were required to choose species that were ranked as "Critically Imperiled" or "Imperiled" in Alabama.

Table 1: Timeline for Rare Species Webpages and Encyclopedia of Alabama Entries

\begin{tabular}{ll}
\hline Week 1 & Students select rare species \\
Week 4 & Checkpoint Assignment for Rare Species Webpage \\
Week 9 & Webpages due \\
Weeks 10-11 & Students receive feedback on webpages \\
Week 12 & Encyclopedia of Alabama entry due \\
Week $13+$ & Editorial development with Encyclopedia of Alabama staff \\
\hline
\end{tabular}

The Rare Species Webpage assignment required students to include information in nine sections: Status, Description, Reproduction, Ecological Information, Habitat Information, Distribution (with a map of the species' occurrence across Alabama counties), Threats, Management Information, and Value of Species. In addition, students included Literature Cited and up to six extra images (see example webpage in the Supplemental Documents). Once students had written the content, they could paste it into a "template" (created by our Instructional Technology office) that would write HTML code around the information, creating an HTML file visible in any browser.

To help students complete the webpages, Boyd assigned a Rare Species Webpage checkpoint assignment. In his previous experience, some students put off the assignment until it was too late for them to generate it, and they either failed to turn in a webpage or turned in poor work. The checkpoint assignment prompted students to begin assembling information on their species and create the Description section (a high point value part) by the $4^{\text {th }}$ week of the semester. The timing allowed Boyd to provide feedback before students turned in their finalized webpage in the $9^{\text {th }}$ week of class. The checkpoint assignment rubric was similar to the final grading rubric for the webpage, so that students would become familiar with webpage grading criteria and standards. (Both rubrics are available in the Supplemental Documents, along with a new departmental rubric for written communication that Boyd plans to adopt in future semesters.)

The EOA entry was due in the $12^{\text {th }}$ week of class to give students time to repackage webpage material based on Boyd's feedback on the webpages. Students did not submit 
drafts of the EOA entry because class size (40-50 students) limited Boyd's time for grading. Instead, Boyd provided supplementary materials to help students complete their projects, including an example of an excellent Rare Species Webpage and several EOA articles published by former students. He also shared a collection of "writing tips" to help students evaluate their writing independently. These included advice about structuring and organizing writing (e.g., using paragraphing and topic sentences), common grammar and spelling errors, and Auburn University's Miller Writing Center.

Out of 46 submissions produced by the Conservation Biology class in fall 2018, EOA editorial staff selected nine for further development as articles. Students were contacted regarding their desire to produce an entry, and then the submission was edited by EOA staff for structure, clarity, and reading level. Additionally, EOA editors queried authors on sections or terminology that needed simplification or expansion to include definitions of scientific language for non-expert readers. The entry was then returned to the author for review and response to queries. As of this writing, six articles from fall 2018 have been published: American black bear, Black Warrior waterdog, hellbender, gentian pinkroot, relict trillium, and Morefield's leather flower (Encyclopedia of Alabama, 2019). Typically, EOA staff chose student submissions primarily for their relevance to the content mission of the encyclopedia, especially species that are endemic to Alabama, historically significant, and of economic or cultural interest. To see an example of successful repackaging, compare the Rare Species Webpage about the American black bear in the supplementary materials to the EOA entry linked above.

\section{Repurposing, reflection, and metacognition}

Amid these assignment changes, we also saw an opportunity to promote the department's new metacognition SLO by adding reflective writing into the mix. A series of guided questions invited students to state the changes they made from webpage to EOA entry, illustrate those changes through selected pieces of text, and comment on what they learned from their efforts. These activities follow two of the higher-order reflective practices articulated by Bain et al. (2002): reconstructing and repackaging. Reconstructing invites metacognition by challenging students to consider future applications and to articulate what knowledge they gained as a result of the experience. Repackaging forces students to think critically about how to honor the richness of the original material as they condense it by learning to focus on the most important or valuable parts, particularly with specific audiences and purposes in mind. As reflective practices, reconstructing and repackaging pair especially well with assignments that require students to repurpose their writing.

When asked to reflect in these ways, almost all (96\%) of the 47 students wrote about the need to condense webpage material to fit EOA's word-count requirement. Most students $(79 \%)$ also commented about revising language and wording to suit the nonexpert EOA audience, although they differed in their approaches. Some (26\%) cut material until they had an EOA entry of the required length; others (53\%) reorganized and/or restructured the material to produce an effective EOA entry. We also found some 
unexpected considerations: some students $(23 \%)$ considered the potential of their EOA entry to motivate readers to take conservation action and included information to drive that motivation. In addition, a few students $(6 \%)$ wrote about making a conscious effort to promote audience engagement by including information that would be most interesting to a non-expert audience. To gauge the success of students' reflective efforts to repurpose their knowledge, we asked their permission to collect their reflections, analyze themes, and share examples.

In the most straightforward reflections, students made changes to fulfill the requirements of the EOA assignment, especially length. For example, one student "took out some [Natural Heritage Program information] in order to meet the word number limit as well as meet the general criteria." Indeed, students' changes often centered on content. Some described such changes using general maxims about summary, such as the student who wrote, "It is important to be able to take a large sum of information and choose the key points." Others were more specific about their reasons for prioritizing certain information. For instance, one student decided to cut a "section about natural causes endangering bats" in favor of discussing "human disturbances" which are "the primary cause of their endangered status." Another student adjusted content to improve the reading experience, writing, "I did really think the courting rituals were fascinating, but it would have taken up too much space in the article and interrupted the flow."

Admittedly, the latter students' reflections stop short of naming audience as a key factor in their revisions, but other students focused on audience explicitly. As one student put it, they needed "to make the EOA entry more palatable" for readers than the webpage. Several did so by repackaging the structure to maintain reader interest, engaging in what one student characterized as "complete reorganization" involving "tough decisions about what, from each section of the webpage, was the true highlight." Another student was direct about the relationship between organization and audience: "I found it necessary to include small factoids and pertinent and interesting information to draw the reader in, but also left room for the reader to explore more details about the species if they feel inclined."

Implicitly or explicitly, all students seemed to recognize the need to adjust technical terminology for different audiences. Typically, students avoided scientific vocabulary altogether, but some students believed a term could not be replaced, such as the student who wrote that "cutaneous respiration is such a key characteristic of amphibians that it needed an explanation." Changes to and definitions of technical terms were particularly valuable for specific audiences, such as non-scientists or secondary-school students, which sometimes factored into students' repurposing decisions explicitly. For example, one student wrote:

When repackaging my information, I thought about a scenario in which a parent is helping their child with a research project. I wanted to put the information in terms that a parent and middle-school-aged child could understand. In keeping with this scenario, I thought about information that 
would be most relevant to a "research project" like that.

This student imagined a specific educational situation in which their EOA entry might be used, with multiple audiences - parent and child — using it to complete a school project. Similarly, several students believed readers might use entries for species identification while others hoped to motivate their audience to get involved with conservation efforts. The range of motives that students considered - and in some cases, did not consider - for reconstructing and repackaging their materials from assignment to assignment have provided us with several ideas for revising the assignment, which we share in the following section.

\section{Reflections and Future Plans}

The above results confirmed the assignment's value for engaging students with the goal of transmitting scientific information to a lay audience. The results also pointed to potential changes in the assignment that might bring out other aspects of communication that we did not initially consider or emphasize. These include:

1. Requiring restructured content and language for the EOA entry. About half of the students did not write about reorganizing the information to improve flow or to consolidate information. We could change the description of the assignment to explicitly recognize that aspect of information repackaging. In addition, one student mentioned adding new information not included in the webpage. We had assumed that repackaging meant removal and reorganization of information in the webpage and had not considered that aspect of repackaging.

2. Encouraging students to consider motivating the reader to value conservation biology. In crafting the original assignment, Boyd assumed that presentation of the technical information was the purpose of the assignment. He did not consider other purposes, such as motivating the reader to take action to conserve a species, but some students considered this in writing their EOA entry. Thus, reader motivation can be added as a goal in repurposing students' webpage information for EOA entries.

3. Increasing emphasis on maintaining reader interest. As with item 2 , reader engagement (defined as motivating the reader to continue reading about the species) was originally not considered as an aspect of the repackaging assignment. Suggesting this additional purpose might stimulate students to consider this aspect in their writing choices, encouraging them to include information that will fascinate a reader. Also, if the Rare Species Webpage assignment explicitly required attention to the interests of scientists or conservationists, students might be better prepared to consider reader engagement in the EOA entry, too.

4. Attention to intellectual property. A number of students included images in both documents, and most made sure to cite the images. However, EOA is unable to 
use copyrighted images without permission. Future iterations of the assignment might introduce students to copyright requirements and open-access resources.

These changes may also help more students recognize the benefit of the EOA assignment. In a final course reflection assignment, one question ("What did you gain from this course's assignments and content as they relate to your career and/or graduate school goal?") was designed to investigate student opinions about the value of course assignments. In response to this question, more students (14) highlighted the value of the webpage, generally writing about its immediate relevance to a student interested in course content (conservation biology), whereas only four mentioned the EOA.

Surprisingly, though, when asked in the final course reflection assignment about how they ranked the importance of the SLOs at the start and end of the class ("Did your top ranking SLO change? Why or why not?"), more students mentioned the EOA entry (8) than the webpage (6), all in the context of writing about the written communication SLO. As an example, one student wrote:

The most valuable aspect of this class, for me, was the Encyclopedia of Alabama entry assignment. The point of the assignment was to learn the ability to speak to a less knowledgeable group, as scientists as a whole can become wrapped up in the academia and forget about education. I would like to open an outreach program for the public, children specifically, and that assignment gave me practice in teaching a group that does not have the same education as me.

This comment showed the potential of this new assignment to expand student horizons in public-oriented directions of the kind discussed in our introduction.

Broadly speaking, this assignment did involve a tradeoff: when two webpages were required of each student, many students commented about having too much work, and that complaint was reduced with this new assignment. From the instructor's standpoint, however, a drawback of the new assignment is that students were not motivated to choose an organism from a group outside their comfort range. Boyd wants students to learn that communities are made up of many different interacting organisms and that basic knowledge of the features of many kinds of organisms can aid conservation efforts. From the EOA's perspective, it is important to present even less charismatic organisms (e.g., worms, insects, and ferns) in an accessible public forum, particularly when they are relevant to Alabama. We might address this concern in future semesters by prioritizing high-need species with EOA's input. If the students are encouraged to select some of these less charismatic species, they may find that presenting them to a non-expert audience can expand their own and their readers' appreciation of the natural world.

As a final note, we recognize that readers may be curious about how to adapt this assignment to their courses. In many ways, this depends on local contexts and resourcesand especially local publications. Faculty interested in developing collaborations with 
content producers aimed at a non-expert audience are encouraged to find out if their state has an online encyclopedia or other such venue. Additionally, university libraries and writing centers will likely be able to provide guidance on identifying outlets for student collaboration. Finally, undergraduate research journals exist in a number of fields and could be valuable outlets for producing public-facing academic writing. Through such options, faculty can encourage students to repurpose their knowledge for multiple audiences and thereby gain a greater appreciation for the potential impacts of their learning.

\section{Assignment: Rare Species Webpage Guidelines}

(To view a PDF facsimile of the original formatting of this assignment, return to this article's homepage and locate the link to the "Assignment" PDF.)

The Rare Species Webpage assignment will require you to use higher-order skills as well as to engage the course material as you write about specific species. Each student will prepare a Rare Species Webpage during the course of the semester. Students may choose a species from a list provided at the start of the semester. In order to focus on rare Alabama species, please select species listed with a State Rank of S1 or S2 only, meaning that they are either Critically Imperiled or Imperiled in the state of Alabama according to the Alabama State Natural Heritage Program (2017). This assignment will enable you to learn specific biological details regarding a rare Alabama species and will help you learn skills used by conservation biologists to find, summarize, analyze, and communicate useful information on rare species. It also will allow you to put concepts and principles covered in class to potential use for conservation of a particular rare species. This exercise also has a possible use beyond the course: Your webpage may be useful if you are building a portfolio of your university coursework to show to prospective employers (especially if you want to work in conservation).

This webpage assignment is similar to writing a research paper regarding a particular rare species. It should be written so that the scientifically savvy reader can understand it, using citations for the information presented so that your source of all information is clearly evident to the reader. Each webpage will contain photos and a summary of all information available on a particular species, emphasizing Alabama but making use of information from other areas if its range is outside the state. It will include a summary of taxonomic, ecological, and distribution information for that species. You should also be alert for information on related species that might indicate something about the rare species. We often know very little about rare species, and any information may be helpful. However, be sure you make clear that a particular item of information was actually collected for another species and is being suggested as appropriate for the rare species. In general, you should always tell the reader where the information you present was found, so they can look it up themselves.

A detailed description of the information for each section of the webpage is provided below: 
1. Status of the species: In this section, provide information on rarity. Give S and $G$ ranks (note that these ranks are NOT state or federal government rankings: they have no official legal significance). When giving a rank, also include a complete definition of the rank (include information on number of occurrences in the definition). This will help us to educate others as to how the ranking systems work. Also give the status of your species on federal and state lists of rare and endangered species: if your species is not listed (maybe because our state does not have an official list for that type of organism?), then be sure to say so! If your species is federally listed, you'll want to include the citation of the listing for your species in the Federal Register (this is very important info for a listed species!). If your species is state-listed in Alabama, explain the conservation meaning of that listing (for example, what does State Protected mean for a species here in Alabama? See information at the front of the Alabama Tracking List for some help with this section).

2. Taxonomic information: Give complete classification below the phylum level. You may find your species has multiple classifications or taxonomic levels not included in the template. In these cases, do what is reasonable to fill out this section as best you can.

3. General description: Provide an overview of the species, including some information on its genus. Give some general information on it and then details for the species. For example, if your species is a duck, do not assume that we all know the general features of ducks. Start general and then move to the specifics. Include specific measurements (length, weight, etc.) for features you describe. Be sure to explain unusual technical words so that a generalist can get an idea of what you are talking about. Try to be as comprehensive as possible, including not only the features of adults but juveniles, eggs, nests, seedlings, seeds, etc. Provide specific differences between this species and others similar to it (including other subspecies if present). Also include ways to tell this species from similar members of other genera, families, etc. This is very helpful information, as it can help someone tell if they have seen a rare species (or have a particular species on their land).

Also include the reference for where the scientific description of the species was first published. In addition, provide any information regarding classification changes that have occurred since the species was first named. The latter information can be very helpful for people interested in learning about a species' taxonomic history. The former can give helpful information on the species' key characteristics, range, etc.

4. Reproduction: This section contains a description of reproduction in the species. Be as specific and complete as possible. Include timing of reproduction (seasonality, age of sexual maturity, length of mating season, courtship and mating behaviors, etc.), need for special habitat locations for reproductive activities (mating, nesting, etc.), and any other pertinent points. If your organism has a larval stage, describe 
it and give information on its habitat needs, food, etc. For plants: information on pollination mode, pollinator type, seed dispersal mode, seed germination, and asexual reproduction should be included here.

5. Ecological Information: This section should include what is known about the ecological relationships of the species. Describe its niche in its community. Note tolerance of the species to disturbance (natural or human-caused), its dependence on other species or ecological value to other species, food habits, etc. We should get a good picture of how your species fits into food webs and if it is affected by any diseases, parasites, etc. Provide ecological information for both adult (mature) forms and larval or seedling forms.

6. Habitat information: Information on the habitat of the species should go in this section. This will include elevation range (maximum and minimum), description of the general type of habitat, and any specific information on soils, geologic substrate, moisture requirements, etc. Important associated species (plants, animals, etc.) should be mentioned again here, even if also noted in the section on ecological information. If available, habitat information should be separated into descriptions of nesting/breeding habitat, mating habitat, hibernation habitat, etc.

7. Management information: Based on ecological requirements, what needs to be done to manage existing populations? For example, note importance of maintaining snags as nesting sites, burning periodically to remove competing vegetation, etc. Are there any activities that can protect populations from disturbance or that can foster a species' recovery? This information may not be available for your species, but general management information for other species in the same habitat is suitable and should be mentioned.

8. Distribution: Tell the reader if your species is found outside of the United States. If not, say so. If so, list the countries or general regions (if it is that widespread). Within the United States, list other states in which the species is found. Provide any available information on commonness or rarity in those states: the Heritage Program state rankings in each of those states would be excellent information, as would information on the status of the species on state lists of threatened or endangered species. Finally, list the counties in Alabama in which the species is known to occur. Counties with historical but extirpated or uncertain status should be noted separately from those in which the species is currently known to occur. Create an Alabama county map showing the counties in which your species occurs. Access the blank map from the course materials, follow directions for downloading the map, and then color in the counties in which your species has been reported.

9. Threats: Here you should note what is actually or potentially threatening survival of the species. If the information is available, this is best done on a population-bypopulation basis, but general statements of threats are acceptable. Be as specific as you can in discussing these threats, providing enough background information 
so the reader can understand the nature of these threats. For example, do not just say lack of fire is a problem, describe why it is a problem for your species.

10. Value of species: Does the species have positive or negative effects on humans? You should define all the different kinds of value that we have discussed in class and describe how your species can be an example of each kind.

11. Cited References: You should have a list of cited references that includes all those you have used to identify specific items of information. This is the most important part of the section, and the sources must be alphabetized so a reader can find a particular reference you have used in your writing. You should prioritize scientific papers published in journals as the references for your information. Books are acceptable as well but should not completely take the place of scientific papers. Websites and popular articles also are acceptable sources, but these should be less than half of your reference citations. Citation styles may vary. So, for consistency, the following citation style for various types of literature is required for our course. For a journal article, provide the following information: Author(s), last name first, with first and middle name initials. Year. Title. Journal name. Volume number of journal: pages of article. Note that an article with more than 2 authors, which should be listed as "Whoever 1 et al. (year)" in the text, now has all authors included when listed in the Cited References section of your webpage. In other words, do not use the expression "et al." in your Cited References section.

Here is an example: Goertzen, L.R., J.L. Trusty and R.S. Boyd. 2011. Clonal diversity and structure in the endangered Alabama leather flower Clematis socialis Kral (Ranunculaceae). Journal of the Torrey Botanical Society 138:41-51.

Books are listed as: Author(s). Year. Title. Publisher and location. Here is an example for an edited book: Boyd, R.S., A.J.M. Baker and J. Proctor. 2004. Ultramafic rocks: their soils, vegetation and fauna. Science Reviews 2000 Ltd, St. Albans, Herts, UK.

A paper published in an edited volume is listed as shown below: Boyd, R.S. 2014. Ecology and evolution of metal-hyperaccumulating plants. In: Rajakaruna, N., R.S. Boyd and T.B. Harris (eds.), pp. 227-241. Plant ecology and evolution in harsh environments. Nova Science Publishers, New York.

A thesis or dissertation should be listed as shown below: Moffett, J.M. 2008. Xyris tennesseensis: Status survey, habitat restoration/management concerns, and relation to a new Xyrid, Xyris spathifolia. Ph.D. dissertation, Auburn University.

To reference a website, give it a title and use the year you accessed it (for example 2018) for the year in the text (ex, Natureserve 2018). Then, in the references section, list this reference as: Natureserve 2018. http://www.natureserve.org/etc and then provide the date on which you accessed the information (e.g., Accessed September 17, 2018). 


\section{EOA Entry}

This portion of the assignment asks you to use the extensive and detailed information you have gathered for your webpage (which is written for a scientific audience) and REPACKAGE that information to make it more accessible to non-experts. So the "appropriate audience" is not the same one as it was for your webpage! In writing for this new audience, you will need to make decisions about what information is important to include, decide how to write it in non-technical language, and reduce your entry to about 1,000 words in total length (not counting the Additional Resources section).

The Encyclopedia of Alabama (EOA; http://www.encyclopediaofalabama.org/), with three full-time staff, is housed here at Auburn University at AU Libraries. The EOA is designed as an educational resource for non-experts and the education community. Because it is intended to be accessible to a non-expert audience, articles must be written so that they are intelligible to citizens that lack specialized scientific training and language.

The following text describes the required elements for your entry.

1. Species common name and your name.

2. Text of entry. You will need to decide how to repackage and reorganize the information in your webpage, as the text of your entry should be roughly 1,000 words. An important writing challenge will be to compose this section so it is accessible to readers with no science background. Technical terms should either be excluded or, if you MUST use them, included with a simplified definition understandable by a non-technical audience. Note that in EOA entries common names (e.g., piping plover) are not capitalized unless they contain a proper noun (e.g., Morefield's leather flower). Also, remember that EOA is Alabama-focused. If your organism is found outside the state, make an effort to emphasize Alabama information in your writing.

3. Additional Resources ( 5 required). Choose five additional resources that you think will be most valuable to someone wanting to learn more about your species. List them alphabetically and by most recent date if more than one by the same author. These resources must not be webpages (unless they give the address of a pdf that can be downloaded). Sources from technical or non-technical journals are preferred (see example EOA entries). Note that the citation style required for EOA differs from that used for your original webpage: follow EOA style as shown in example entries. Also note that EOA does not include in-text citations in its entries.

4. Figures (up to three to obtain maximum points in Content Category: see rubric). In this section of your EOA document, insert each figure into the document (using "Insert Photo" in MS Word). Below each one, write a brief figure legend using the simple style seen in the example entries provided for this assignment. Attempt to find images that are fair use or copyright free, where possible.

5. Explanation of Information Repackaging. As you design your EOA entry, you will 
need to make decisions about what information to include. This last section of the entry asks you to REFLECT on your decisions and explain how you decided what information was important enough to include in the EOA entry. As you think about this section, consider the purpose of the EOA entry, its non-technical audience, and the goal of helping Alabamians learn about conservation of organisms in our state.

6. Example of Information Repackaging. In this section, I ask you to illustrate your repackaging process by including a block of original information, the repackaged version, and a narrative describing why you made the choices that you did in the repackaging process.

\section{References}

Alabama Natural Heritage Program. (2017). Alabama inventory list: The rare, threatened and endangered plants $\mathcal{E}$ animals of Alabama. Auburn University, AL: Alabama Natural Heritage Program.

Artemeva, N. (2005). A time to speak, a time to act: A rhetorical genre analysis of a novice engineer's calculated risk taking. Journal of Business and Technical Communication, $19(4), 389-421$.

Bain, J. D., Ballantyne, R., Mills, C., \& Lester, N. C. (2002). Reflecting on practice: Student teachers' perspectives. Flaxton, Queensland: Post Pressed.

Bazerman, C. (1988). What written knowledge does: Three examples of academic discourse. In Shaping written knowledge: The genre and activity of the experimental article in science (pp. 18-55). Madison, WI: The University of Wisconsin Press.

Brewer, C., \& Smith, D. (Eds.). (2009). Vision and change in undergraduate biology education: A call to action. Washington, DC: American Association for the Advancement of Science.

Ceballos, G., Ehrlich, P. R., Barnosky, A. D., García, A., Pringle, R. M., \& Palmer, T. M. (2015). Accelerated modern human-induced species losses: Entering the sixth mass extinction. Science Advances, 1(5), e1400253.

Cook, C. N., Mascia, M. B., Schwartz, M. W., Possingham, H. P., \& Fuller, R. A. (2013). Achieving conservation science that bridges the knowledge-action boundary. Conservation Biology, 27(4), 669-678.

Encyclopedia of Alabama. (2019). http://eoa.auburn.edu.

Gere, A. R., Limlamai, N., Wilson, E., Saylor, K., \& Pugh, R. (2019). Writing and conceptual learning in science: An analysis of assignments. Written Communication, $36(1), 99-135$. 
Moon, A., Gere, A. R., \& Shultz, G. V. (2018). Writing in the STEM classroom: Faculty conceptions of writing and its role in the undergraduate classroom. Science Education, 102(5), 1007-1028.

Prior, P., \& Shipka, J. (2003). Chronotopic lamination: Tracing the contours of literate activity. In C. Bazerman \& D. Russell (Eds.), Writing selves/writing societies: Research from activity perspectives (pp. 180-238). Fort Collins, CO: WAC Clearinghouse.

Roozen, K. (2010). Tracing trajectories of practice: Repurposing in one student's developing disciplinary writing processes. Written Communication, 27(3), 318-354.

Schaal, B. (2017). Informing policy with science. Science, 355 (6324), 435.

Tardy, C. M. (2005). Expressions of disciplinarity and individuality in a multimodal genre. Computers and Composition, 22(3), 319-336. 